\title{
Development and Validation of a Stability-indicating HPLC-UV Method for the Simultaneous Determination of Flurbiprofen and Triclosan in Dental Nanogel Formulations
}

\author{
Nafiu Aminu, ${ }^{1,2^{*}}$ Siok-Yee Chan ${ }^{1}$ and Seok-Ming Toh $^{1 * *}$ \\ ${ }^{1}$ Discipline of Pharmaceutical Technology, School of Pharmaceutical Sciences, \\ Universiti Sains Malaysia, 11800 USM Pulau Pinang, Malaysia \\ ${ }^{2}$ Department of Pharmaceutics and Pharmaceutical Microbiology, Faculty of \\ Pharmaceutical Sciences, Usmanu Danfodiyo University, P.M.B. 2346, Sokoto, Nigeria \\ Corresponding authors: "nafiu.aminu@udusok.edu.ng; **smtoh@usm.my
}

Published online: 25 February 2018

To cite this article: Aminu, N., Chan, S-Y. \& Toh, S-M. (2018). Development and validation of a stability-indicating HPLC-UV method for the simultaneous determination of flurbiprofen and triclosan in dental nanogel formulations. J. Phys. Sci., 29(Supp. 1), 1-7, https://doi.org/10.21315/jps2018.29.s1.1

To link to this article: https://doi.org/10.21315/jps2018.29.s1.1

\begin{abstract}
A combination of two drugs involving flurbiprofen (FLB) and triclosan (TCS) has been found to be potential treatment candidates against periodontal disease. In the present study, a new, simple, reliable and stability-indicating high performance liquid chromatography (HPLC) method for the simultaneous determination of FLB and TCS in the dental nanogel (NGs) formulation has been introduced. The chromatographic

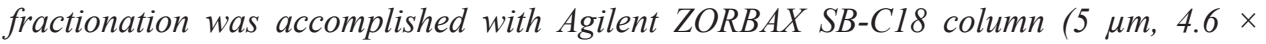
$250 \mathrm{~mm}$ ), using a mixture of acetonitrile and $8 \times 10^{-4}$ mol $l^{-1}$ citric acid, $\mathrm{pH} 3.26$ (90:10, $v / v)$ as a mobile phase, under isocratic elution mode with a flow rate of $0.3 \mathrm{ml} \mathrm{min}{ }^{-1}$. The $U V$ detection was set at $242 \mathrm{~nm}$. The method was validated according to ICH guidelines. Results indicated excellent linearity with a correlation coefficient of 0.999 and 1 for $F L B$ and TCS, respectively. The retention time $\left(t_{R}\right)$ was found to be $10.11 \pm 0.03$ and $12.55 \pm 0.02$ min for FLB and TCS, respectively. Extensive stress degradation studies of acidic/alkaline hydrolysis, oxidative, photolytic and heat degradation demonstrated good specificity and stability-indicating power of the method. The method was found to be simple, specific and could be employed for the simultaneous determination of FLB and TCS in dental formulations and for routine quality control evaluations.
\end{abstract}

Keywords: Simultaneous determination, stability-indicating HPLC-UV method, dental formulation, flurbiprofen, triclosan 


\section{INTRODUCTION}

Modern medicine is gradually changing its approach with an increased focus on drug combination therapy in recent years. Many clinicians and other health practitioners are now suggesting combination therapy for a lot of disorders because of its ability to achieve synergistic therapeutic effects, hit multiple targets, decrease toxicity, minimise drug resistance, and improve the therapeutic profile. ${ }^{1}$ Dentistry is not left out in this pace of development as there are various drug combination therapies that have proved promising for the treatment of dental diseases. ${ }^{2,3}$ Advances in nanotechnology-based delivery systems such as nanoparticles (NPs) and nanogels (NGs) have enabled more efficient delivery of a myriad of drugs to the desired site of action. ${ }^{3}$ A suitable formulation of FLB (analgesic, anti-inflammatory) and TCS (broad-spectrum antimicrobial) combination would be highly desirable for periodontal therapy, owing to the therapeutic efficacy of the drugs.

Although there are reported methods for the estimation of FLB and TCS in their separate forms, a suitable validated stability indicating analytical method for the simultaneous quantification of these drugs is still lacking., ${ }^{4,5}$ Thus, this study was undertaken to develop and validate a stability-indicating high performance liquid chromatography-ultraviolet (HPLC-UV) method for the simultaneous determination of FLB and TCS in NG formulations.

\section{EXPERIMENTAL}

\subsection{Materials}

FLB was purchased from FDC Ltd., India. TCS was purchased from Bio Basic Canada Inc., Canada. Poly-e-caprolactone (PCL), Chitosan and Kolliphor ${ }^{\circledR}$ P188 were from Sigma-Aldrich, USA. AR grade hydrochloric acid $(\mathrm{HCl})$, hydrogen peroxide $\left(\mathrm{H}_{2} \mathrm{O}_{2}\right)$ and acetone were purchased from $Q R e C^{\circledR}$ Asia (Malaysia). Citric acid anhydrous and sodium hydroxide $(\mathrm{NaOH})$ pellets were from R\&M, UK. HPLC grade acetonitrile and methanol was from Merck (Germany). Water was produced in-house by the Favorit W4L water system (Genristo Ltd. UK).

\subsection{HPLC Apparatus}

A Shimadzu (Japan) HPLC system (LC-20AD) was used for the analysis. An Agilent ZORBAX SB-C18 column $(5 \mu \mathrm{m}, 4.6 \times 250 \mathrm{~mm})(\mathrm{USA})$ was used for the chromatographic separations. The column temperature was set at $30^{\circ} \mathrm{C}$. Ten $\mu 1$ injection volumes of calibration standard solutions/test samples were analysed without further dilution, under an isocratic elution mode. 


\subsection{Preparation of Standard Solutions and Standard Calibration Curves}

To prepare the stock standard solution, $30 \mathrm{mg}$ and $20 \mathrm{mg}$ of FLB and TCS, respectively, were weighed and dissolved in $100 \mathrm{ml}$ of methanol to produce a $300 \mu \mathrm{g} \mathrm{ml} l^{-1}$ of FLB and $200 \mu \mathrm{g} \mathrm{ml}^{-1}$ of TCS solution. From this solution, different concentration levels were prepared using methanol as a diluting solvent, to obtain working calibration solutions of FLB and TCS in the ranges of 15-240 $\mu \mathrm{g} \mathrm{ml}^{-1}$ and $10-160 \mu \mathrm{g} \mathrm{ml}^{-1}$, respectively. Each solution was injected in six replicates into the HPLC system. The peak areas were plotted against the corresponding concentrations to yield the standard calibration curves of FLB and TCS.

\subsection{Preparation of the NGs Formulation Sample}

NGs were prepared using a three-stage procedure. Firstly, TCS-loaded NPs were prepared according to our reported method. ${ }^{6}$ Secondly, $3 \%$ of FLB loaded chitosan hydrogel was prepared according to a published method. ${ }^{2}$ The NGs was prepared by entwinement of TCS-loaded NPs into the FLB-loaded hydrogel solution. Similarly, blank NGs were prepared without any FLB and TCS content. The real test samples were prepared by treating an amount of the NGs in methanol to yield a supernatant (originated after centrifugation) with a final concentration of $75 \mu \mathrm{g} \mathrm{ml}^{-1}$ and $50 \mu \mathrm{g} \mathrm{ml}^{-1}$ of FLB and TCS, respectively. Similarly, an unloaded NG sample was prepared.

\subsection{Stress Degradation Studies}

The stock standard solution for stress studies was prepared by dissolving an amount of FLB and TCS in methanol to correspond with concentrations of $1200 \mu \mathrm{g} \mathrm{ml}^{-1}$ of FLB and $800 \mu \mathrm{g} \mathrm{m}^{-1}$ of TCS. The stock test solution was prepared as described in Section 2.4 but with tenfold concentrations. The stress degradation studies were conducted on the standard and test samples as described in the reported method, but with differences in the strengths of $\mathrm{HCl}, \mathrm{NaOH}$ and $\mathrm{H}_{2} \mathrm{O}_{2}{ }^{7}$ In the proposed method, $2 \mathrm{M} \mathrm{HCl}, 2 \mathrm{M} \mathrm{NaOH}$ and $30 \% \mathrm{H}_{2} \mathrm{O}_{2}$ solutions were used as degradation factors, and $10 \mu \mathrm{l}$ of the sample solutions were filtered $(0.45 \mu \mathrm{m}$ syringe filters) and injected into the HPLC system.

\subsection{Method Validation}

The proposed HPLC method was validated according to ICH guidelines and the validation characteristics such as system suitability, linearity, range, accuracy, precision, specificity, limit of detection (LOD) and limit of quantification (LOQ) were assessed. ${ }^{8}$ The linearity of the calibration graph was demonstrated by preparing eight different concentrations of standard solutions over a range 
of 15-300 $\mu \mathrm{g} \mathrm{ml}^{-1}$ and 10-200 $\mu \mathrm{g} \mathrm{ml}^{-1}$ for FLB and TCS, respectively. For the assessment of accuracy and precision, three QC samples of FLB and TCS were prepared from the standard stock solution. The accuracy was established by the recovery of the FLB and TCS from the three QC samples (37.5, 75 and $112.5 \mu \mathrm{g} \mathrm{ml}^{-1}$ of FLB and 25, 50 and $75 \mu \mathrm{g} \mathrm{ml}^{-1}$ of TCS, respectively) and NGs formulation. Intra-day and inter-day precision were determined by repeated injections ( $n=6$ ) of the quality control (QC) samples within the same day and on six consecutive different days. System suitability testing was carried out by injecting 10 replicates of the standard and test sample solutions. To demonstrate specificity, chromatograms of FLB and TCS of standard solutions were compared with chromatograms of methanol, mobile phase and the test solutions with and without the analytes. The specificity was further confirmed by stress degradation studies. The LOD and LOQ were determined based on the signal-to-noise ratio of 3 and 10 , respectively.

\section{RESULTS AND DISCUSSION}

\subsection{Method Development and Validation}

Selection of mobile phase involved testing various mobile phase solvents (methanol, acetonitrile, citric acid, citrate buffer and distilled water) at different combination ratios. Following several experimental trials, FLB and TCS were successfully separated with the solvent combination of acetonitrile, i.e., $8 \times 10^{-4} \mathrm{~mol}^{-1}$ citric acid ( $\mathrm{pH} 3.26$ ), ratio 90:10, $v / v$ under isocratic condition.

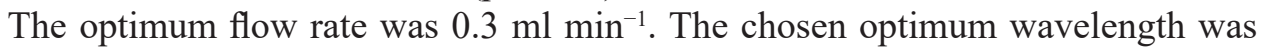
$242 \mathrm{~nm}$ which provided the best sensitivity for both the analytes. The HPLC chromatogram under optimal conditions is depicted in Figure 1(c). The $t_{\mathrm{R}}$ for FLB and TCS were around $10.11 \mathrm{~min}$ and $12.55 \mathrm{~min}$, respectively. The validation results are summarised in Table 1. Excellent linearity was achieved for both calibration curves. Accuracy and precision were calculated as percentage (\%) recovery and percentage RSD of the NGs and QC sample solutions, and the results indicated satisfactory recoveries for both drugs. The specificity of the method was adequate as there was no interference (Figure 1). The LOD found for both analytes is much lower than that of the reported method for FLB $\left(0.03 \mu \mathrm{g} \mathrm{ml}^{-1}\right)$, and $\operatorname{TCS}\left(2 \mu \mathrm{g} \mathrm{ml}^{-1}\right) .4$

\subsection{Stress Degradation Studies}

No substantial degradation observed (data not shown), except in the acid hydrolysis study which revealed a significant degradation $(60 \%)$ of FLB in $2 \mathrm{M} \mathrm{HCl}$ atmosphere after $24 \mathrm{~h}$ exposure. Contrarily, potentiation effect was observed for 
TCS when it was subjected to acid stress for $24 \mathrm{~h}$, with more than $300 \%$ increase. The exact mechanism of this synergy should be investigated in future.

\section{CONCLUSION}

A novel, simple, specific and stability-indicating HPLC method for the simultaneous quantification of FLB and TCS was developed and validated. The analytes were extracted from the nanogel formulation and quantified without any interference from the excipient constituents or impurities. The stress degradation studies revealed that $2 \mathrm{M} \mathrm{HCl}$ exerts an antagonistic effect on FLB but on the contrary, a pronounced synergistic effect with TCS. The method could be employed in the simultaneous determination of FLB and TCS in dental formulations.

Table 1: The proposed method validation results.

\begin{tabular}{|c|c|c|c|}
\hline Parameter & Flurbiprofen & Triclosan & $\begin{array}{c}\text { Acceptable } \\
\text { limits }^{8,9}\end{array}$ \\
\hline \multicolumn{4}{|l|}{ System suitability $(n=10)$} \\
\hline $\mathrm{t}_{\mathrm{R}}( \pm \mathrm{SD})$ & $10.11(0.03)$ & $12.55(0.02)$ & - \\
\hline Tailing factor $( \pm \mathrm{SD})$ & $1.45(0.07)$ & $0.98(0.03)$ & $\leq 2$ \\
\hline Number of theoretical plates $( \pm \mathrm{SD})$ & $8160(592)$ & $4575(238)$ & $>2000$ \\
\hline Resolution $( \pm \mathrm{SD})$ & $2.50(0.13)$ & $3.97(0.30)$ & $>2$ \\
\hline Injection repeatability (\% RSD) & 0.14 & 0.09 & $\leq 1 \%$ \\
\hline \multicolumn{4}{|l|}{ Linearity and range } \\
\hline Regression equation & $\begin{aligned} y= & (149431) x+ \\
& (-118634)\end{aligned}$ & $\begin{aligned} y= & (67450.0) x+ \\
& (59777.6)\end{aligned}$ & - \\
\hline $\mathrm{R}^{2}$ & 0.9991 & 1 & $>0.999$ \\
\hline Ranges $\left(\mu \mathrm{g} \mathrm{ml}^{-1}\right)$ & $15-300$ & $10-200$ & - \\
\hline \multicolumn{4}{|l|}{ Accuracy } \\
\hline Average recovery (\%) & $97.93^{\mathrm{a}}, 103.18^{\mathrm{b}}$ & $96.07^{\mathrm{a}}, 99.28^{\mathrm{b}}$ & $100 \pm 2 \%$ \\
\hline Average R.E. (\%) & $-2.07^{\mathrm{a}}, 3.18^{\mathrm{b}}$ & $-3.93^{\mathrm{a}},-0.72^{\mathrm{b}}$ & $\pm 2 \%$ \\
\hline Average RSD (\%) & $0.32^{\mathrm{a}}, 0.25^{\mathrm{b}}$ & $0.18^{\mathrm{a}}, 0.66^{\mathrm{b}}$ & - \\
\hline \multicolumn{4}{|l|}{ Precision } \\
\hline Intra-day precision(\% RSD) & 0.41 & 0.75 & $\leq 2 \%$ \\
\hline Inter-day precision(\% RSD) & 1.32 & 0.98 & $\leq 2 \%$ \\
\hline $\operatorname{LOD}\left(\mu \mathrm{g} \mathrm{ml}^{-1}\right)(\% \mathrm{RSD})$ & 0.01 & 0.02 & - \\
\hline LOQ $\left(\mu \mathrm{g} \mathrm{ml}^{-1}\right)(\% \mathrm{RSD})$ & 0.03 & 0.06 & - \\
\hline
\end{tabular}

Notes: R.E. = Relative error; ${ }^{a}$ nanogel formulation $(n=6) ;{ }^{b} Q C$ samples at three concentration levels $(n=6)$ 


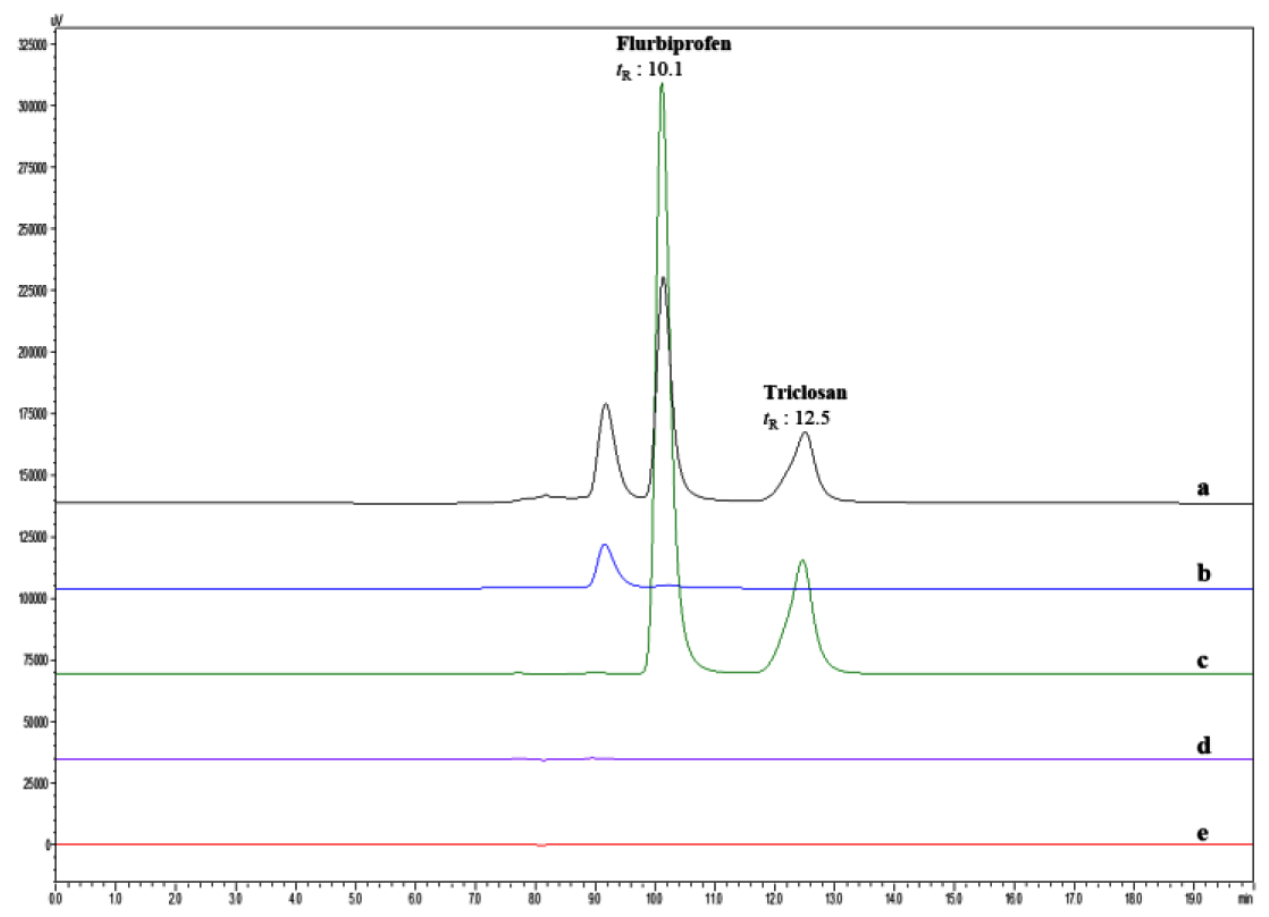

Figure 1: Chromatograms of loaded NGs formulation (a); unloaded NGs formulation (b); standard solution (c); methanol (d) and mobile phase (e) of the proposed method.

\section{ACKNOWLEDGEMENTS}

The authors wish to gratefully acknowledge the financial support provided by Universiti Sains Malaysia through the USM Fellowship Scheme and the ShortTerm Grant Scheme (304/PFARMASI/6315018).

\section{REFERENCES}

1. Chou, T. C. (2010). Drug combination studies and their synergy quantification using the Chou-Talalay method. Cancer Res., 70(2), 440-446, https://doi. org/10.1158/0008-5472.CAN-09-1947.

2. Popa, L., Ghica, M. V. \& Dinu-Pîrvu, C. E. (2013). Periodontal chitosangels designed for improved local intra-pocket drug delivery. Farmacia, $61(2), 240-250$. 
3. Aminu, N. \& Toh, S. (2017). Applicability of nanoparticles-hydrogel composite in treating periodontal diseases and beyond. Asian J. Pharm. Clin. Res., 10(2), 65-70, https://doi.org/10.22159/ajpcr.2017.v10i2.15709.

4. Yilmaz, B. \& Erdem, A. F. (2015). Determination of flurbiprofen in human plasma by high-performance liquid chromatography. J. Chromatogr. Sci., 53(9), 1443-1448, https://doi.org/10.1093/chromsci/bmv032.

5. Piccoli, A., Fiori, J., Andrisano, V. \& Orioli, M. (2002). Determination of triclosan in personal health care products by liquid chromatography (HPLC). Farmaco, 57(5), 369-372, https://doi.org/10.1016/S0014827X(02)01225-9.

6. Aminu, N. et al. (2013). Development and evaluation of triclosan loaded poly- $\varepsilon$-caprolactone nanoparticulate system for the treatment of periodontal infections. J. Nanopart. Res., 15(11), 2075, https://doi.org/10.1007/s11051013-2075-6.

7. Syed, H. K. et al. (2015). Stability indicating HPLC-UV method for detection of curcumin in Curcuma longa extract and emulsion formulation. Food Chem., 170, 321-326, https://doi.org/10.1016/j.foodchem.2014.08.066.

8. ICH. (2005). Validation of analytical procedures: Text and methodology. Paper presented at the International Conference on Harmonisation of Technical Requirements for Registration of Pharmaceuticals for Human Use, Chicago, September.

9. Shabir, G. A. (2003). Validation of high-performance liquid chromatography methods for pharmaceutical analysis. J. Chromatogr. A, 987(1-2), 57-66, https://doi.org/10.1016/S0021-9673(02)01536-4. 